\title{
Individual differences in behavioral consistency are related to sequential access to resources and body condition in a producer-scrounger game
}

\author{
Morgan David ${ }^{1,2,3 * t}$, Mewen Le Hô ${ }^{4}$, Kate L. Laskowski ${ }^{5}$, Marion Salignon ${ }^{2}$, Mark A. F. Gillingham ${ }^{2,6,7}$ \\ and Luc-Alain Giraldeau ${ }^{1}$
}

' Département des Sciences Biologiques, Université du Québec à Montréal, Montréal, OC, Canada

${ }^{2}$ Équipe Écologie Évolutive, UMR CNRS 6282 Biogéosciences, Université de Bourgogne, Dijon, France

${ }^{3}$ Centre for Ecology and Conservation, School of Biosciences, College of Life and Environmental Sciences, University of Exeter, Penryn, UK

${ }^{4}$ Département de Sciences Biologiques, Université de Montréal, Montréal, QC, Canada

${ }^{5}$ Department of Biology and Ecology of Fishes, Leibniz Institute for Freshwater Ecology and Inland Fisheries, Berlin, Germany

${ }^{6}$ Department of Evolutionary Genetics, Leibniz Institute for Zoo and Wildlife Research, Berlin, Germany

${ }^{7}$ Centre de Recherche de la Tour du Valat, Arles, France

\section{Edited by:}

Sasha Raoul Xola Dall, University of

Exeter, UK

\section{Reviewed by:}

Pierre Bize, University of Aberdeen, UK

Pim Edelaar, University Pablo de Olavide, Spain

\section{*Correspondence:}

Morgan David, Department of Biology - Ethology, University of Antwerp, Drie Eiken Campus, Universiteitsplein 1, 2610 Wilrijk, Belgium

e-mail:morgan.david@gmx.fr

${ }^{\dagger}$ Present address:

Morgan David, Department of Biology - Ethology, University of

Antwerp, Wilrijk, Belgium
Investigating the evolution of consistent between-individual behavioral differences necessitates to explain the emergence of within-individual consistency. Relying on a recent mathematical model, we here test the prediction that the emergence of differences in within-individual consistency is related to the sequential access to resources in a frequency-dependent foraging game. To this end we used flocks of zebra finches (Taeniopygia guttata) engaged in a producer-scrounger foraging game. Tactic investment (i.e., the proportion of hops with the head down) significantly predicted successful tactic use (i.e., the proportion of seeds produced). In support of predictions, we found that individuals that arrived first at a foraging area were more consistent in both their investment into and their use of the producer tactic. Also, birds in higher body condition were less consistent in their producer tactic use. These results provide the first evidence that variation in behavioral consistency can emerge through the sequential access to resources in a frequency-dependent game. They also highlight a potential physiological cost of behavioral flexibility. Our findings suggest an explanation for the link between personality traits and social information use.

Keywords: behavioral flexibility, body condition, exploration, intra-individual variability, social foraging, state-dependence, personality, Taeniopygia guttata

\section{INTRODUCTION}

Behavioral ecology assumes that organisms have either evolved adaptive fixed traits over the course of generations or the required flexibility which enables them to adopt adaptive behavior according to local environmental conditions (the so-called "behavioral gambit") (Fawcett et al., 2013). The idea of unique adaptive traits is thus increasingly challenged by the growing number of cases where animals of the same population differ consistently in their behavior (also called animal "personalities") (Réale et al., 2007; Kight et al., 2013). Explaining the origin of such within-population variation necessitates the identification of the factors favoring both among-individual behavioral differences and within-individual consistency (Dingemanse and Wolf, 2013; Kight et al., 2013).

The maintenance of among-individual behavioral differences is thought to be linked with multiple evolutionary processes (Dingemanse and Wolf, 2010; Réale et al., 2010a). For instance, life-history/behavior co-evolution (Biro and Stamps, 2008; Réale et al., 2010b; Nicolaus et al., 2012), sexual selection processes (Reaney and Backwell, 2007; Schuett et al., 2010; Pruitt et al., 2011), or fluctuating selection pressures (Dingemanse et al., 2004; Quinn et al., 2009; Dochtermann et al., 2012) are all thought to promote among-individual differences within animal populations. However, explaining why and when within-individual consistency can emerge remains an end in itself that deserves investigation (Kight et al., 2013). The ultimate factors favoring within-individual behavioral consistency remain little explored (McNamara et al., 2009; Dingemanse and Wolf, 2013; Kight et al., 2013). Whereas behavior is traditionally thought of as being highly flexible, recent evidence has highlighted individual differences in behavioral consistency (e.g., "intra-individual variability," David et al., 2012a; Stamps et al., 2012; Briffa et al., 2013; Laskowski and Bell, 2013). These recent findings, associated with the development of theory-based predictions about the evolution of within-population behavioral differences (Wolf et al., 2008; Dingemanse and Wolf, 2010), suggest that within-individual consistency may be shaped by natural selection. Determining how and why variation in individual consistency can emerge and be maintained within populations is thus crucial to providing a complete account of the evolution of consistent among-individual behavioral differences.

Using a simulation model, Dubois et al. (2012) recently investigated how differences in within-individual consistency can emerge in a situation where individual payoffs are 
frequency-dependent. The model assumes that when arriving at a foraging area, individuals that arrive first have no opportunity to utilize the findings of others (i.e., scrounge) and so are left with no other option than producing (i.e., actively searching for food). It also predicts that these early arrivals should show persistent producer tactic use over a single foraging bout. Therefore, when individuals are consistent in their arrival order over different foraging episodes, they are also predicted to be more consistent in their use of the producer tactic (Dubois et al., 2012). In this situation the frequency-dependence of expected payoffs is thought to make both consistent and flexible tactic use co-existing and thus to prevent the flexible strategy from being an evolutionary stable strategy (Dubois et al., 2012). In the present paper we use zebra finches (Taeniopygia guttata), a ground-feeding passerine bird species foraging in flocks, to test the prediction that first-arriving individuals express a greater within-individual consistency in both their investment into and their use of the producer foraging tactic (Dubois et al., 2012). Body condition was controlled for as previous findings indicate that it may negatively affect behavioral consistency (David and Giraldeau, 2012).

\section{METHODS}

\section{STUDY SUBJECTS}

Fifteen adult male and 15 adult female zebra finches were commercially purchased and kept in same-sex flocks of 2-3 individuals in small home cages $(1 \times \mathrm{h} \times \mathrm{w}: 52 \times 38 \times 29 \mathrm{~cm})$. Room temperature was maintained at $24 \pm 1^{\circ} \mathrm{C}$ on a $12: 12 \mathrm{~h}$ light:dark cycle (0800-2000 h). Millet seeds, water, and cuttlebones were provided ad libitum while vegetables and an egg mixture were occasionally offered. Zebra finches are small passerine birds that forage in large flocks in the wild. Feeding flocks are formed either by individuals joining others already feeding on the ground or by individuals landing in a cohesive flock (Zann, 1996). Here we extended the analyses of previously published data from the same foraging trials where exploration behavior, foraging tactic use, and arrival order on the foraging grid were found to be repeatable (David et al., 2011a).

\section{ASSESSMENT OF BODY CONDITION}

Eight days before the experiments, individuals were weighed twice to the nearest $0.01 \mathrm{~g}$ using an electronic balance, and tarsus length was measured twice to the nearest $0.1 \mathrm{~mm}$ using a digital caliper. Measurements of weight [Pearson's $r_{(29)}=0.98, p<0.0001$ ] and tarsus length $\left[r_{(29)}=0.79, p<0.0001\right]$ were significantly repeatable (David and Giraldeau, 2012). Body condition was assessed from the residuals of the linear regression of $\log _{10}$ (weight) on $\log _{10}$ (tarsus length).

\section{EXPLORATION TRIALS}

Exploration behavior was assessed by placing birds alone in a novel environment cage $(120 \times 120 \mathrm{~cm}$ and $60 \mathrm{~cm}$ high $) \mathrm{com}$ posed of five artificial trees with four branches each. Exploration score was determined as the number of movements between trees and branches of the same tree during $1 \mathrm{~h}$. Trials were performed twice at a 1-week interval and exploration scores individually averaged. Birds were sorted into four categories according to their averaged exploration score: low-exploratory, mediumexploratory, high-exploratory birds, and a fourth category of individuals for which exploration scores were unknown. See David et al. (2011a) for more details.

\section{FORAGING TRIALS}

Foraging trials were run 1 week after the last exploration trial. Birds foraged in unisex feeding flocks of four individuals that were unfamiliar to each other ( $n=6$ flocks) sorted on the basis of their exploration score for the purpose of another study (one bird of each exploration category in each flock) (David et al., 2011a). The experimental aviaries $(1 \times \mathrm{w} \times \mathrm{h}: 1.5 \times 3.8 \times 2.3 \mathrm{~m})$ held a foraging grid $(1.2 \times 1.2 \mathrm{~m})$ containing 64 wells $(1.6 \mathrm{~cm}$ in diameter and $1 \mathrm{~cm}$ deep) spaced at every $8.1 \mathrm{~cm}$ (see Figure 2 in David et al., 2014), two perches and two water dispensers outside the grid. The general procedure consisted of two identical, consecutive 3-day experimental sessions. On the first day of each session, each bird of a given flock was ringed with a unique combination of blue and light blue leg rings to allow for individual identification (David et al., 2011a). Then each of the six flocks was allowed into an experimental aviary with all 64 wells of the foraging grid filled with millet seeds. Over the next 2 days, birds were fooddeprived for $1 \mathrm{~h}$ before the first trial (David et al., 2011a, 2012b), and performed one 12-min trial every hour for $5 \mathrm{~h}$. Before each trial, 10 randomly selected wells were filled with five white millet seeds each and then birds were free to access the grid and forage on it. Birds were not fed between trials. Trials were videorecorded on the third day of each session only, to ensure that all birds were familiar with the foraging grid and the experimental conditions. Birds were then allowed to rest in groups of three in home cages for 4 consecutive days before undergoing the same 3-day procedure but with different flock-mates (second session). However, it was impossible to form three same-sex flocks in the second session with a totally different composition from that in the first session. Therefore, we introduced three new males and three new females in the second session. Also, due to a lack of available birds, two individuals were tested together in the same flock in both sessions. More details can be found in David et al. (2011a).

\section{BEHAVIORAL OBSERVATIONS}

Data were collected from the three trials of the third day of each session, which is sufficient to provide a reliable estimate of food searching behavior. For each trial we recorded birds' arrival order on the grid with the individual landing first being given the score 1 and last bird the score 4 . For each bird we recorded the number of hops performed with the head pointed down and with the head pointed up, thought to reflect the investment into producer and scrounger tactic, respectively (more details provided in David et al., 2014; see also Coolen et al., 2001; Wu and Giraldeau, 2005). We quantified both the investment into a given tactic ("tactic investment") and the actual number of seeds obtained through this tactic ("tactic use"). The latter has been shown to be related to the number of full wells discovered or scrounged (David et al., 2011a). For each trial and each individual we derived the proportion of hops with the head down from the number of hops with the head down divided by the total number of hops with the head 
down and up. Then we calculated each individual's variance in the proportion of hops with the head down among trials of the same session as an index of its consistency in tactic investment.

For each individual we recorded the number of seeds produced, i.e., found and ingested from a previously undiscovered well, and the number of seeds scrounged, i.e., eaten from a well where flock-mates were already feeding. The seeds ingested by a given individual can easily be recorded as zebra finches perform highly stereotypic bill movements when separating the seed from the husk (Zann, 1996). In most cases, the husk can be seen falling from the bill, indicating that a seed has been ingested. Using this behavior we counted the number of seeds a bird ate from produced or scrounged wells. For each trial and each individual we derived the proportion of seeds produced from the number of seeds produced divided by the total number of seeds produced and scrounged. Then we calculated each individual's variance in the proportion of seeds produced among trials of the same session, as an index of its consistency in actual tactic use.

As first arrivals on the foraging grid are left with no other options than producing, the possibility remains that a positive relationship between variance in the proportion of seeds produced and arrival order may result from a higher reliance on producer tactic use in the very first instants of a trial, before flock mates land on the grid. To rule out this potential "early effect," we separately collected the same data once all individuals had landed on the foraging grid. Thus, we computed the "adjusted proportion of seeds produced," corresponding to the proportion of seeds produced estimated once all individuals have landed on the grid. Then we derived for each individual the variance in the adjusted proportion of seeds produced among trials.

\section{STATISTICAL ANALYSES}

All statistical analyses were carried out using the statistical freeware R-2.14.1 (R Development Core Team, 2012). We investigated behavioral consistency at the population level by calculating the repeatability $(R)$ of each behavior within and between sessions using the "rptR" package (Nakagawa and Schielzeth, 2010). Between-session repeatability of "proportion of hops with the head down" were computed using the between-individual covariance of this behavior across sessions using additive overdispersion Generalized Linear Mixed Models (GLMMs) with Markov Chain Monte Carlo (MCMC) estimation (Dingemanse and Dochtermann, 2013). These types of analyses provide a 95\% Credible Interval (CrI) for the repeatability estimate, which we use to determine significance, but no $p$-value: if an estimate's $\mathrm{CrI}$ does not overlap zero we consider that repeatability estimate to be significantly different from zero.

Our main research question was to determine whether arrival order influenced within-individual consistency in tactic investment and tactic use. We tested the influence of arrival order on individual variance in tactic investment, tactic use, and adjusted tactic use separately for each behavior and each experimental session using GLMMs with Gaussian error structure. The dependent variable was log-transformed to reach normality. Arrival order, exploration category, and the interaction between arrival order and sex were included as predictors. As body condition has previously been shown to affect variance in tactic use in the same trials
(David and Giraldeau, 2012), we added the interaction between body condition and arrival order as a predictor in the models. In all models we included "flock" as a random intercept to control for the non-independence of individual behavior within flocks. We provided Cohen's $d$ and their 95\%Confidence Interval (CI) as effect size (Nakagawa and Cuthill, 2007), and correlation coefficients between continuous predictors and response variables but without $95 \% \mathrm{CI}$ as they are not reliable when computed from mixed models (Nakagawa, pers. commun.). Additionally we tested whether the proportion of seeds obtained by producing was influenced by the investment in either tactic by testing if the proportion of hops with head down predicted the proportion of seeds produced using a GLMM fitted with binomial error structure, and individual ID nested within flock as a random intercept.

\section{RESULTS}

\section{INDIVIDUAL VARIANCE IN TACTIC USE IS REPEATABLE}

The proportion of hops with the head down was only slightly repeatable (1st session: $R=0.05,95 \%$ CrI [0.02;0.13]; 2nd session: $R=0.08,95 \% C r I$ [0.04;0.17]; between sessions: $R=0.23$, $95 \% \operatorname{CrI}[-0.08 ; 0.62])$. Individual variance in the proportion of hops with head down was not repeatable between the two sessions $(R=-0.27,95 \% C I[-0.74 ; 0.20])$ whereas individual variance in the proportion of seeds produced was highly repeatable $(R=0.47,95 \% C I[0.04 ; 0.89])$. The repeatability estimates of both arrival order and proportion of seeds produced have been reported in David et al. (2011a), where they were found to overall be repeatable within, but not across, sessions.

\section{HOPS WITH HEAD DOWN PREDICT SEEDS PRODUCED}

The proportion of hops with the head down significantly influenced the proportion of seeds produced $\left(\chi^{2}=18.8, d f=1, p<\right.$ 0.0001 ; Spearman's $r_{s}=0.23$, Figure 1). Thus, the more a bird hopped with the head down, the more it was likely to use the

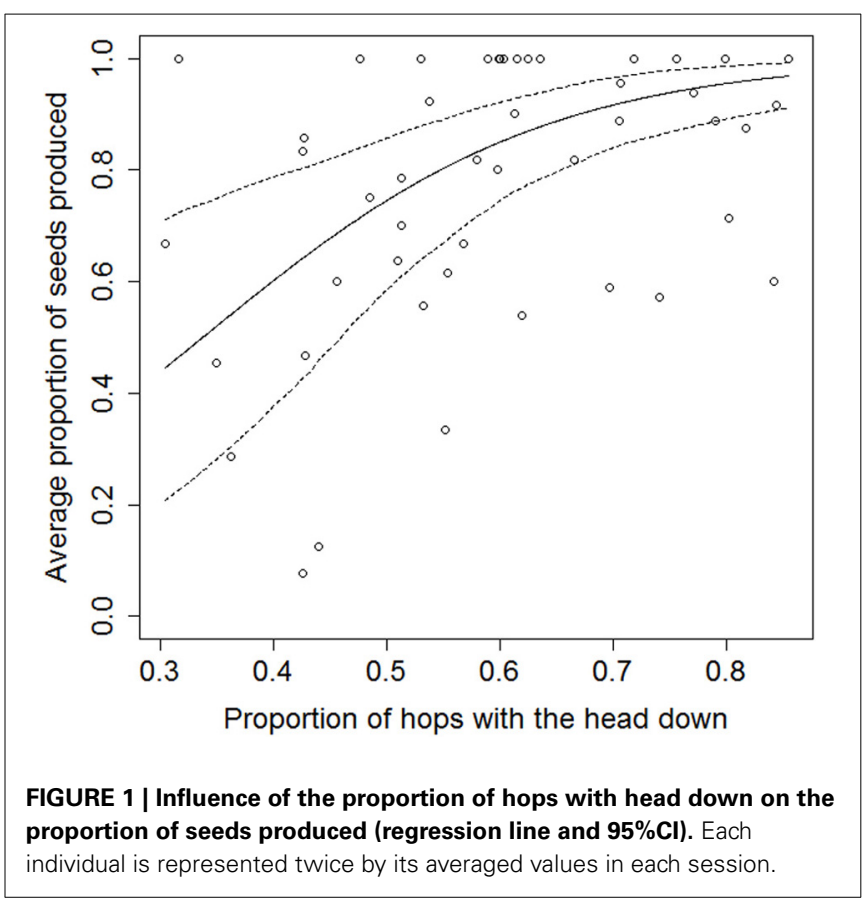


producer tactic. Conversely, the more a bird hopped with the head up, the more it was likely to scrounge seeds from the discoveries of flock-mates.

\section{INDIVIDUALS THAT ARRIVE FIRST ARE MORE CONSISTENT IN TACTIC INVESTMENT AND TACTIC USE}

Birds within a flock landed on the grid in a median time interval of $7.50 \mathrm{~s}$ (interquartile range: $5-14.75 \mathrm{~s}$, minimum: $3 \mathrm{~s}$, maximum: $54 \mathrm{~s}$.). This represents a median percentage of time of $7.39 \%$ of the total time needed for birds to discover all filled wells (interquartile range: $4.69-9.66 \%$, minimum: $2.52 \%$, maximum: $19.08 \%$ ) during which foragers were not all on the grid at the same time (once they started foraging, birds rarely left the grid before the trial ended).

An individual's average arrival order on the foraging grid had a positive influence on its variance in the proportion of hops with the head down during the second experimental session $[b \pm$ $S E=0.42 \pm 0.20$, Pearson's $r_{(22)}=0.39$; Table 1, Figure 2C], but not the first $\left[b \pm S E=-0.09 \pm 0.21, r_{(22)}=-0.09\right.$; Table 1, Figure 2A]. That is, individuals that arrived first exhibited lower variance in the proportion of hops with the head down across trials, at least in the second session. Body condition had no influence on the variance in the proportion of hops with the head down in either session (1st session: $b \pm S E=8.19 \pm 7.16, r_{s}=$ 0.28 ; 2nd session: $b \pm S E=-1.45 \pm 5.55, r_{s}=-0.11$; Table 1). Exploration category did not predict variance in the proportion of hops with the head down in either session (Table 1), nor was there any significant interaction between sex and arrival order. However, females showed, on average, higher variance in the proportion of hops with the head down than males in the second session $[$ mean (females) $=0.026$; mean (males $)=0.009$; Cohen's $d=0.935 ; 95 \%$ CI $[0.053 ; 1.817]$; Table 1], but not in the first session $[$ mean $($ females $)=0.024$; mean $($ males $)=0.023$; Cohen's $d=0.046 ; 95 \%$ CI $[-0.811 ; 0.903]$; Table 1$]$.

The variance in the proportion of seeds produced across trials was positively predicted by individual average arrival order during both first $\left[b \pm S E=0.89 \pm 0.41, r_{(19)}=0.44\right.$; Table 1, Figure 2B] and second sessions $\left[b \pm S E=0.84 \pm 0.34, r_{(22)}=\right.$ 0.46; Table 1, Figure 2D]. Body condition positively affected the variance in the proportion of seeds produced in both sessions (1st session: $b \pm S E=28.60 \pm 12.59, r_{s}=0.37 ; 2$ nd session: $b \pm S E=19.79 \pm 9.16, r_{s}=0.26$; Table 1). Exploration category had no influence on the variance in the proportion of seeds produced in either session (Table 1), nor was there any significant interaction between sex and arrival order (Table 1). Males and females did not differ in their variance in the proportion of seeds produced, either in the first session [mean (females $)=0.040$; mean $($ males $)=0.089$; Cohen's $d=-0.508 ; 95 \% C I[-0.326 ; 1.378]$; Table 1$]$ or in the second session $[$ mean $($ females $)=0.049$; mean $($ males $)=0.065$; Cohen's $d=-0.184 ; 95 \%$ CI $[-0.655 ; 1.023]$; Table 1 $]$.

The variance in the adjusted proportion of seeds produced was significantly affected by arrival order (1st session: $b \pm S E=$ $0.80 \pm 0.38, r_{s}=0.47 ; 2$ nd session: $b \pm S E=0.81 \pm 0.30, r_{s}=$ 0.30 ; Table 1) and body condition (1st session: $b \pm S E=24.83 \pm$ $12.59, r_{s}=0.35 ;$ 2nd session: $b \pm S E=18.42 \pm 8.96, r_{s}=0.28$; Table 1) only.
Table 1 | Results of the models testing the factors affecting variance in tactic investment, tactic use, and adjusted tactic use, both in the first and the second session.

\begin{tabular}{|c|c|c|c|c|c|c|}
\hline \multirow{2}{*}{$\begin{array}{l}\text { Response variable } \\
\text { Predictors }\end{array}$} & \multicolumn{3}{|c|}{ 1st session } & \multicolumn{3}{|c|}{ 2nd session } \\
\hline & $x^{2}$ & $d f$ & $\boldsymbol{P}$ & $x^{2}$ & $d f$ & $\boldsymbol{P}$ \\
\hline \multicolumn{7}{|c|}{ VARIANCE IN THE PROPORTION OF HOPS WITH HEAD DOWN } \\
\hline Sex & 0.16 & 1 & 0.69 & 4.30 & 1 & 0.04 \\
\hline Arrival order & 0.39 & 1 & 0.53 & 4.77 & 1 & 0.03 \\
\hline Body condition & 1.39 & 1 & 0.24 & 0.09 & 1 & 0.77 \\
\hline Exploration category & 3.55 & 3 & 0.31 & 1.38 & 3 & 0.71 \\
\hline Arrival order $\times$ Sex & 0.44 & 1 & 0.51 & 3.45 & 1 & 0.06 \\
\hline $\begin{array}{l}\text { Arrival order } \times \text { Body } \\
\text { condition }\end{array}$ & 0.77 & 1 & 0.38 & 0.04 & 1 & 0.84 \\
\hline Arrival order $\times$ Exploration & 3.85 & 3 & 0.28 & 1.44 & 3 & 0.70 \\
\hline
\end{tabular}

category

VARIANCE IN THE PROPORTION OF SEEDS PRODUCED

$\begin{array}{lllllll}\text { Sex } & 0.68 & 1 & 0.41 & 0.53 & 1 & 0.47 \\ \text { Arrival order } & \mathbf{4 . 0 9} & \mathbf{1} & \mathbf{0 . 0 4} & \mathbf{6 . 5 8} & \mathbf{1} & \mathbf{0 . 0 1} \\ \text { Body condition } & \mathbf{5 . 2 9} & \mathbf{1} & \mathbf{0 . 0 2} & \mathbf{4 . 6 3} & \mathbf{1} & \mathbf{0 . 0 3} \\ \text { Exploration category } & 4.23 & 3 & 0.24 & 4.36 & 3 & 0.23 \\ \text { Arrival order } \times \text { Sex } & >0.01 & 1 & 0.99 & 0.29 & 1 & 0.59 \\ \text { Arrival order } \times \text { Body } & >0.01 & 1 & 0.95 & 0.67 & 1 & 0.41 \\ \text { condition } & & & & & & \\ \text { Arrival order } \times \text { Exploration } & 0.23 & 3 & 0.97 & 5.99 & 3 & 0.11\end{array}$

category

VARIANCE IN THE ADJUSTED PROPORTION OF SEEDS PRODUCED

$\begin{array}{lllllll}\text { Sex } & >0.01 & 1 & 0.98 & 0.81 & 1 & 0.37\end{array}$

Arrival order

Body condition

Exploration category

Arrival order $\times$ Sex

Arrival order $\times$ Body

$\begin{array}{llllll}4.55 & 1 & 0.03 & 6.62 & 1 & 0.01\end{array}$

condition

Arrival order $\times$ Exploration

$\begin{array}{lll}4.11 & 1 & 0.04\end{array}$

$2.73 \quad 3-0.43 \quad 4.08 \quad 3.04$

$\begin{array}{llllll}0.01 & 1 & 0.92 & 0.29 & 1 & 0.65\end{array}$

$\begin{array}{llllll}>0.01 & 1 & 0.98 & 0.84 & 1 & 0.36\end{array}$

category

Significant effects are highlighted in bold. The adjusted proportion of seeds produced has been computed from data collected after all individuals had landed on the grid.

Thus, birds arriving first on the foraging grid were more consistent in their investment in the producer tactic, at least in the second session, and more consistent in its successful use in both sessions. The same results held when using data collected after all birds had landed on the grid. Birds in higher body condition were also less consistent in their producer tactic use, but not in their investment into producing.

\section{DISCUSSION}

Within-individual consistency in tactic use (i.e., variances computed within sessions) was found to be repeatable across two separate foraging sessions. We also found that an individual's consistency in tactic investment and tactic use was predicted by its arrival order on the foraging grid, when the influence of exploration behavior and body condition was controlled for. Our results provide the first evidence that arrival order can impact 


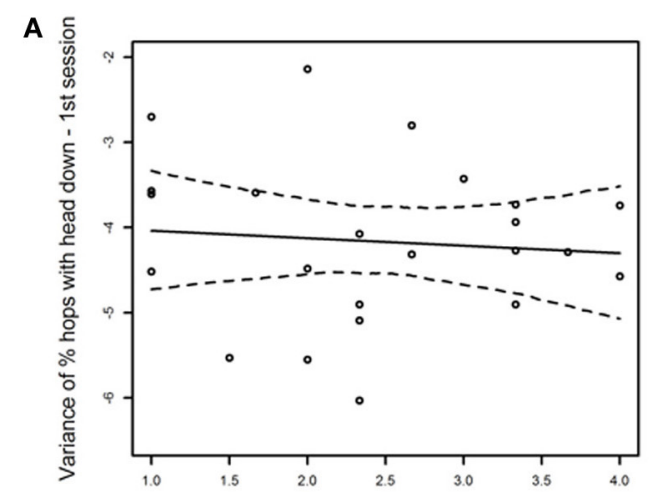

C

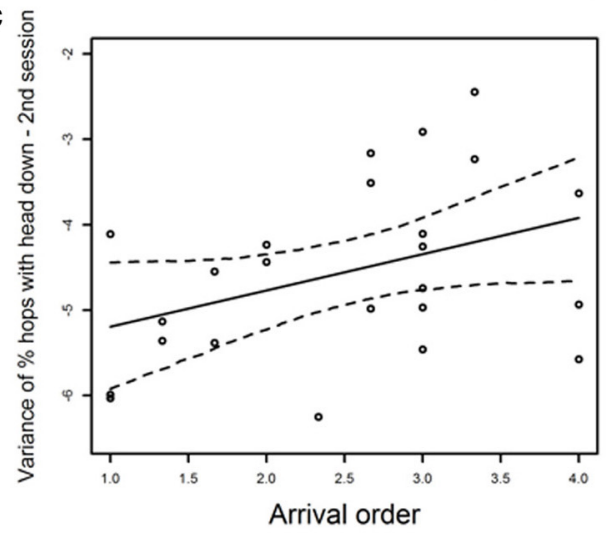

FIGURE 2 | Influence of arrival order on the variance in proportion of hops with the head down (log-transformed) in first (A) and second session (C), and on the variance in proportion of seeds produced

within-individual behavioral consistency, providing a potential mechanism for the emergence of consistent among-individual behavioral differences. Below we discuss each of our findings and their limitations and emphasize their implications for our understanding of the evolution of within-population variation.

\section{THE CONSISTENCY OF FORAGING BEHAVIOR}

Individual variance in the proportion of seeds produced was repeatable between sessions, indicating that birds differed in tactic use consistency, i.e., intra-individual variability (David et al., 2012a; Stamps et al., 2012; Briffa et al., 2013). However, individual investment in the producer tactic based on hopping behavior (Coolen et al., 2001; Wu and Giraldeau, 2005; David et al., 2014) was only slightly repeatable. Our finding that the proportion of hops with head down predicts the proportion of seeds produced extends earlier results obtained with nutmeg mannikins Lonchura punctulata, increasing confidence that a ground feeding bird's proportion of hops with the head down, or investment into producing, reliably reflects actual and successful tactic use (Coolen et al., 2001; Wu and Giraldeau, 2005).

We found that females and males did not differ in their consistency, except in the second session where females displayed higher variance in their proportion of hops with head down. This latter result is consistent with the hypothesis that behavioral consistency can differ between sexes (Schuett and Dall, 2009; Jenkins, 2011; Hedrick and Kortet, 2012) and perhaps in itself be sexually

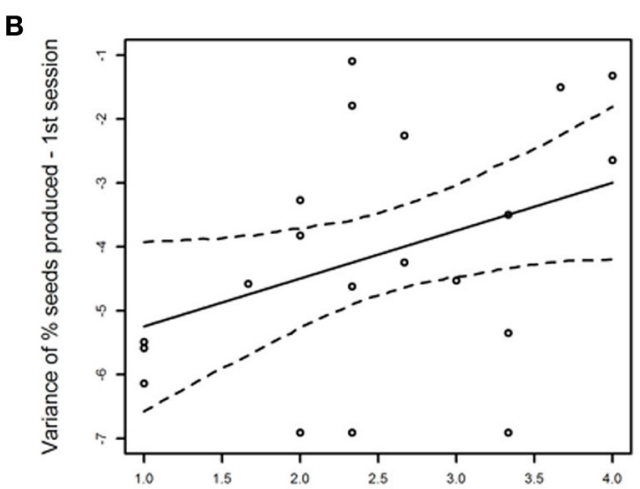

D

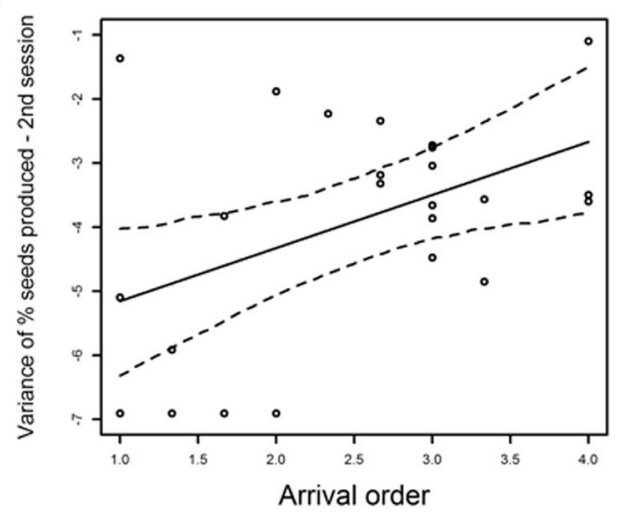

(log-transformed) in first (B) and second session (D). Thick line is the regression line surrounded by its $95 \% \mathrm{Cl}$. Arrival order was averaged across trials of a given session.

selected (Schuett et al., 2010). Overall yet, our findings offer only limited support for this hypothesis.

\section{SEQUENTIAL ACCESS TO RESOURCES AND BEHAVIORAL CONSISTENCY}

Birds arriving first on the foraging grid were more consistent in the number of seeds produced during both sessions and during the second session they invested more consistently in the producer tactic. Overall, these findings support Dubois et al.'s predictions that in a frequency-dependent situation arrival order may promote persistent differences in behavioral consistency (Dubois et al., 2012), under the assumption that arrival order is consistent (David et al., 2011a). First arrivals have no other choice than producing when entering a new foraging area, and they then may be expected to play producer more consistently over the foraging bout. However, we have shown that the effect still holds when using data collected after all birds had landed on the grid (cf. the adjusted proportion of seeds produced). This indicates that the link between arrival order and the consistency in producer tactic use cannot only be accounted for a higher reliance on producing early in the trial. Supporting another prediction of Dubois et al.s' model (2012), birds arriving first on the grid were found to produce more than late-arriving birds in another study using the same foraging trials (David et al., 2011a). So far we are unable to determine whether a higher consistency in producing is the cause or the mere consequence of a stronger use of the producer 
tactic by early arrivals (David et al., 2011a). Indeed, under the null assumption, individuals using the producer tactic in extremely low or high proportions are, from a strict statistical viewpoint, expected to display less variation, and thus be more consistent, in their foraging tactic use. For the same reason, low variances may have resulted from weak foraging activity. However, variances in the proportion of hops with the head down or of seeds produced were not related to the total number of hops performed on the grid (results not shown).

An obvious area for future research is to investigate the mechanisms that allow differences in consistency in tactic investment and tactic use to persist. In Dubois et al.s' model (2012), foragers land on the patch sequentially after the previous one went through only one foraging decision (either producing or scrounging). This means that even early arrivals quickly have the opportunity to scrounge from conspecifics' discoveries, leaving the question of why early arrivals keep producing in a consistent way open. One could have expected first-arriving individuals to produce in a consistent way until sufficient flock-mates are present to provide opportunities to scrounge. However, foragers followed one another on the grid within a few seconds most of the time (see Results), and the effect of arrival order on variance in the proportion of seeds produced was still significant when using data collected after all birds had landed on the grid. It thus appears that first arrivals did not take advantage of scrounging opportunities but kept relying on producing even after flock mates have joined. The reasons why first arrivals do not increase their scrounging behavior over the foraging bout remain to be explored. It may be that early arrival and producing behavior are both related to a third variable which diminishes first arrivals' likelihood to flexibly switch between tactics. Also, birds in poor body condition produced more consistently and thus were less flexible in the use of producer and scrounger tactic, suggesting that perhaps the energy costs of flexibility may have promoted differences in behavioral consistency, along with a sequential access to the foraging grid. Overall, further studies should explore whether and why individuals remain consistent in their foraging tactic use over long periods after their arrival at the feeding patch (van Overveld and Matthysen, 2013).

\section{SOCIAL INFORMATION USE AND PERSONALITY TRAITS}

Our findings may provide the missing functional link between the joint study of personality traits and social information use (Nomakuchi et al., 2009; David et al., 2011a; Dubois et al., 2012). Dubois et al. (2012) propose that the sequential use of any type of resources may link personality traits with social information use (i.e., here scrounger tactic use), with first-arriving individuals potentially being bolder and hence more likely to produce (Dubois et al., 2012). In support of this argument, an earlier study has linked arrival order on a foraging area with personality traits such as risk-taking or exploration (David et al., 2011b). This was not found in the current study as arrival order was unrelated to exploration behavior (David et al., 2011a) but a recent study demonstrated that a zebra finch's latency to engage in a foraging activity was linked to the proactive/reactive continuum (David et al., 2012b). Our results suggest that it would be worth exploring further the extent to which sequential decisions in frequency-dependent situations can promote individual differences in behavioral consistency in other animal systems and explain interindividual variation in the tendency to use social information.

\section{CONCLUSION}

Overall, our findings provide evidence that sequential access to resources and body condition may promote persistent differences in behavioral consistency in a frequency-dependent foraging game. Our results can have important implications for an understanding of the emergence of behavioral consistency in animal populations. They also highlight a possible functional link between social information use and personality traits, and in this regard contribute to establishing predictions that could be tested in further studies.

\section{ETHICAL STANDARDS}

All procedures were approved under protocol 0210-676-0211 of the University of Quebec at Montreal (UQAM)'s committee for animal care, and thus complied with the Canadian legislation.

\section{ACKNOWLEDGMENTS}

Thanks to François-Xavier Dechaume-Moncharmont for statistical advice. We would also like to thank two referees for their valuable comments on the original manuscript. Morgan David and the research were both financially supported through a Natural Sciences and Engineering Research Council (Canada) Discovery Grant to Luc-Alain Giraldeau. Morgan David received additional financial support from Fondation UQAM, and from a Fonds Québecois de la Recherche sur la Nature et les Technologies' Frontenac Scholarship.

\section{REFERENCES}

Biro, P. A., and Stamps, J. A. (2008). Are animal personality traits linked to life-history productivity? Trends Ecol. Evol. 23, 361-368. doi: 10.1016/j.tree.2008.04.003

Briffa, M., Bridger, D., and Biro, P. A. (2013). How does temperature affect behaviour? Multilevel analysis of plasticity, personality and predictability in hermit crabs. Anim. Behav. 86, 47-54. doi: 10.1016/j.anbehav.2013.04.009

Coolen, I., Giraldeau, L.-A., and Lavoie, M. (2001). Head position as an indicator of producer and scrounger tactics in a ground-feeding bird. Anim. Behav. 61, 895-903. doi: 10.1006/anbe.2000.1678

David, M., Auclair, Y., and Cézilly, F. (2011b). Personality predicts social dominance in female zebra finches, Taeniopygia guttata, in a feeding context. Anim. Behav. 81, 219-224. doi: 10.1016/j.anbehav.2010.10.008

David, M., Auclair, Y., and Cézilly, F. (2012a). Assessing short- and long-term repeatability and stability of personality in captive zebra finches using longitudinal data. Ethology 118, 932-942. doi: 10.1111/j.1439-0310.2012.02085.x

David, M., Auclair, Y., Giraldeau, L.-A., and Cézilly, F. (2012b). Personality and body condition have additive effects on motivation to feed in Zebra Finches Taeniopygia guttata. Ibis 154, 372-378. doi: 10.1111/j.1474-919X.2012.01216.x

David, M., Cézilly, F., and Giraldeau, L.-A. (2011a). Personality affects zebra finch feeding success in a producer-scrounger game. Anim. Behav. 82, 61-67. doi: 10.1016/j.anbehav.2011.03.025

David, M., Gillingham, M. A. F., Salignon, M., Laskowski, K. L., and Giraldeau, L.-A. (2014). Speed-accuracy trade-off and its consequences in a scramble competition context. Anim. Behav. 90, 255-262. doi: 10.1016/j.anbehav.2014.02.009

David, M., and Giraldeau, L.-A. (2012). Zebra finches in poor condition produce more and consume more food in a producer-scrounger game. Behav. Ecol. 23, 174-180. doi: 10.1093/beheco/arr171

Dingemanse, N. J., Both, C., Drent, P. J., and Tinbergen, J. M. (2004). Fitness consequences of avian personalities in a fluctuating environment. Proc. R. Soc. Lond. B Biol. Sci. 271, 847-852. doi: 10.1098/rspb.2004.2680 
Dingemanse, N. J., and Dochtermann, N. A. (2013). Quantifying individual variation in behaviour: mixed-effect modelling approaches. J. Anim. Ecol. 82, 39-54. doi: 10.1111/1365-2656.12013

Dingemanse, N. J., and Wolf, M. (2010). Recent models for adaptive personality differences: a review. Philos. Trans. R. Soc. B Biol. Sci. 365, 3947-3958. doi: $10.1098 /$ rstb.2010.0221

Dingemanse, N. J., and Wolf, M. (2013). Between-individual differences in behavioural plasticity within populations: causes and consequences. Anim. Behav. 85, 1031-1039. doi: 10.1016/j.anbehav.2012.12.032

Dochtermann, N. A., Jenkins, S. H., Swartz, M. J., and Hargett, A. C. (2012). The roles of competition and environmental heterogeneity in the maintenance of behavioral variation and covariation. Ecology 93, 1330-1339. doi: 10.1890/111025.1

Dubois, F., Giraldeau, L.-A., and Réale, D. (2012). Frequency-dependent payoffs and sequential decision-making favour consistent tactic use. Proc. R. Soc. Lond. B Biol. Sci. 279, 1977-1985. doi: 10.1098/rspb.2011.2342

Fawcett, T. W., Hamblin, S., and Giraldeau, L.-A. (2013). Exposing the behavioral gambit: the evolution of learning and decision rules. Behav. Ecol. 24, 2-11. doi: 10.1093/beheco/ars085

Hedrick, A. V., and Kortet, R. (2012). Sex differences in the repeatability of boldness over metamorphosis. Behav. Ecol. Sociobiol. 66, 407-412. doi: 10.1007/s00265011-1286-Z

Jenkins, S. H. (2011). Sex differences in repeatability of food-hoarding behaviour of kangaroo rats. Anim. Behav. 81, 1155-1162. doi: 10.1016/j.anbehav.2011.02.021

Kight, C. R., David, M., and Dall, S. R. X. (2013). "The evolution of animal personality variation," in Encyclopedia of Life Sciences, ed H. Kehrer-Sawatzki (Chichester: John Wiley and Sons Ltd.), 1-8. doi: 10.1002/9780470015902.a0024662

Laskowski, K. L., and Bell, A. M. (2013). Competition avoidance drives individual differences in response to a changing food resource in sticklebacks. Ecol. Lett. 16, 746-753. doi: 10.1111/ele.12105

McNamara, J. M., Stephens, P. A., Dall, S. R. X., and Houston, A. I. (2009). Evolution of trust and trustworthiness: social awareness favours personality differences. Proc. R. Soc. Lond. B Biol. Sci. 276, 605-613. doi: 10.1098/rspb.2008.1182

Nakagawa, S., and Cuthill, I. C. (2007). Effect size, confidence interval and statistical significance: a practical guide for biologists. Biol. Rev. 82, 591-605. doi: 10.1111/j.1469-185X.2007.00027.x

Nakagawa, S., and Schielzeth, H. (2010). Repeatability for Gaussian and nonGaussian data: a practical guide for biologists. Biol. Rev. 85, 935-956. doi: 10.1111/j.1469-185X.2010.00141.x

Nicolaus, M., Tinbergen, J. M., Bouwman, K. M., Michler, S. P. M., Ubels, R., Both, C., et al. (2012). Experimental evidence for adaptive personalities in a wild passerine bird. Proc. R. Soc. Lond. B Biol. Sci. 279, 4885-4892. doi: 10.1098/rspb.2012.1936

Nomakuchi, S., Park, P. J., and Bell, M. A. (2009). Correlation between exploration activity and use of social information in three-spined sticklebacks. Behav. Ecol. 20, 340-345. doi: 10.1093/beheco/arp001

Pruitt, J. N., Riechert, S. E., and Harris, D. J. (2011). Reproductive consequences of male body mass and aggressiveness depend on females' behavioral types. Behav. Ecol. Sociobiol. 65, 1957-1966. doi: 10.1007/s00265-011-1205-3

Quinn, J. L., Patrick, S. C., Bowhuis, S., Wilkin, T. A., and Sheldon, B. C. (2009). Heterogeneous selection on a heritable temperament trait in a variable environment. J. Anim. Ecol. 78, 1203-1215. doi: 10.1111/j.1365-2656.2009.01585.x
R Development Core Team. (2012). R: A Language and Environment For Statistical Computing. Vienna: R Foundation for Statistical Computing. ISBN 3-900051-07-0.

Réale, D., Dingemanse, N. J., Kazem, A. J. N., and Wright, J. (2010a). Evolutionary and ecological approaches to the study of personality. Philos. Trans. R. Soc. B Biol. Sci. 365, 3937-3946. doi: 10.1098/rstb.2010.0222

Réale, D., Garant, D., Humphries, M. M., Bergeron, P., Careau, V., and Montiglio, P. -O. (2010b). Personality and the emergence of the pace-of-life syndrome concept at the population level. Philos. Trans. R. Soc. B Biol. Sci. 365, 4051-4063. doi: 10.1098/rstb.2010.0208

Réale, D., Reader, S. M., Sol, D., McDougall, P. T., and Dingemanse, N. J. (2007). Integrating animal temperament within ecology and evolution. Biol. Rev. 82, 291-318. doi: 10.1111/j.1469-185X.2007.00010.x

Reaney, L. T., and Backwell, P. R. Y. (2007). Risk-taking behavior predicts aggression and mating success in a fiddler crab. Behav. Ecol. 18, 521-525. doi: 10.1093/beheco/arm014

Schuett, W., and Dall, S. R. X. (2009). Sex differences, social context and personality in zebra finches, Taeniopygia guttata. Anim. Behav. 77, 1041-1050. doi: 10.1016/j.anbehav.2008.12.024

Schuett, W., Tregenza, T., and Dall, S. R. X. (2010). Sexual selection and animal personality. Biol. Rev. 85, 217-246. doi: 10.1111/j.1469-185X.2009.00101.x

Stamps, J. A, Briffa, M., and Biro, P. A. (2012). Unpredictable animals: individual differences in intraindividual variability (IIV). Anim. Behav. 83, 1325-1334. doi: 10.1016/j.anbehav.2012.02.017

van Overveld, T., and Matthysen, E. (2013). Personality and information gathering in free-ranging great tits. PLoS ONE 8:e54199. doi: 10.1371/journal.pone.0054199

Wolf, M., Sander van Doorn, G., and Weissing, F. J. (2008). Evolutionary emergence of responsive and unresponsive personalities. Proc. Natl. Acad. Sci. U.S.A. 105, 15825-15830. doi: 10.1073/pnas.0805473105

Wu, G. M., and Giraldeau, L.-A. (2005). Risky decisions: a test of risk sensitivity in socially foraging flocks of Lonchura punctulata. Behav. Ecol. 16, 8-14. doi: 10.1093/beheco/arh127

Zann, R. A. (1996). The Zebra Finch: A Synthesis of Field and Laboratory Studies. Oxford: Oxford University Press. ISBN: 978-0198540793.

Conflict of Interest Statement: The authors declare that the research was conducted in the absence of any commercial or financial relationships that could be construed as a potential conflict of interest.

Received: 12 January 2014; accepted: 02 May 2014; published online: 22 May 2014. Citation: David M, Le Hô M, Laskowski KL, Salignon M, Gillingham MAF and Giraldeau L-A (2014) Individual differences in behavioral consistency are related to sequential access to resources and body condition in a producer-scrounger game. Front. Ecol. Evol. 2:19. doi: 10.3389/fevo.2014.00019

This article was submitted to Behavioral and Evolutionary Ecology, a section of the journal Frontiers in Ecology and Evolution.

Copyright (c) 2014 David, Le Hô, Laskowski, Salignon, Gillingham and Giraldeau. This is an open-access article distributed under the terms of the Creative Commons Attribution License (CC BY). The use, distribution or reproduction in other forums is permitted, provided the original author(s) or licensor are credited and that the original publication in this journal is cited, in accordance with accepted academic practice. No use, distribution or reproduction is permitted which does not comply with these terms. 